\title{
Catalyzed Diesel Particulate Filter Performance in A Light-Duty Vehicle
}

\author{
C. Scott Sluder and Brian H. West \\ Oak Ridge National Laboratory (ORNL)
}

\begin{abstract}
Light-duty chassis dynamometer driving cycle tests were conducted on a Mercedes A170 diesel vehicle with various sulfur-level fuels and exhaust emission control systems. Triplicate runs of a modified light-duty federal test procedure (FTP), US06 cycle, and SCO3 cycle were conducted with each exhaust configuration and fuel. Ultralow sulfur (3-ppm) diesel fuel was doped to 30- and 150ppm sulfur so that all other fuel properties remained the same. The fuels used in these experiments met the specifications of the fuels from the DECSE (Diesel Emission Control Sulfur Effects) program.
\end{abstract}

Although the Mercedes A170 vehicle is not available in the United States, its emissions in the as tested condition fell within the U.S. Tier 1 full useful life standards with the OEM catalysts installed. Tests with the OEM catalysts removed showed that the OEM catalysts reduced PM emissions from the engine-out condition by $30-40 \%$ but had negligible effects on NOx emissions. Fuel sulfur level had very little effect on the OEM catalyst performance.

A prototype catalyzed diesel particulate filter (CDPF) mounted in an underfloor configuration reduced particulate matter emissions by more than $90 \%$ compared to the factory emissions control system. The results show that the CDPF did not promote any significant amounts of $\mathrm{SO}_{2}-$ to-sulfate conversion during these light-duty drive cycles.

\section{INTRODUCTION}

As manufacturers continue to increase the fuel economy of cars and trucks, direct-injection and lean-burn technologies have become a focus area for both spark ignited (SI) and compression-ignition $(\mathrm{Cl})$ engines. Emissions control for lean-burn technologies, both for $\mathrm{SI}$ and $\mathrm{Cl}$ engines, remains a challenge. As a result, several organizations have undertaken research aimed at producing devices to reduce the emissions from lean burn engines.

As these devices are being developed, other efforts have estimated the potential emissions reductions from prototype devices and investigated the effects of fuel sulfur on the devices. One of these is the Diesel Emission Control Sulfur Effects (DECSE) program. This program evaluated the performance of several diesel emission control technologies with ultra-low sulfur No. 2 diesel fuel doped to various sulfur levels. All performance evaluations were carried out on stationary dynamometer test stands, and most were at steady state conditions. Performance tests showed the effects of fuel sulfur on device effectiveness and sulfate emissions. Devices evaluated under the auspices of DECSE included diesel oxidation catalysts, lean NOx catalysts, continuously regenerating diesel particulate filters, catalyzed diesel particulate filters, and NOx adsorbers (1-4).

The Diesel Vehicle Emission Control Sulfur Effects (DVECSE) project was designed to augment and build on the DECSE program. Time and resource limitations constrained the first phase of DVECSE to one NOx adsorber and one catalyzed diesel particulate filter evaluation. The vehicle's baseline emissions were measured for both the engine-out condition and with original equipment manufacturer (OEM) catalysts installed.

The vehicle tests discussed in this were intended to enhance the DECSE program by evaluating emissions control devices during transient driving cycles. The goals were to quantify the emissions reduction potential of some of these near-term emission control devices and to examine the effects of fuel sulfur on their performance. This paper focuses on evaluation of a catalyzed diesel 
particulate filter; a companion paper focuses on evaluations carried out on a NOx adsorber (5).

\section{THEORY OF CDPF OPERATION}

The concept of a diesel particulate filter (DPF) is not a new one. Development has been underway for a number of years, particularly in Europe, on devices aimed at filtering the particulate emissions from diesel engine exhaust streams. Previously, these devices were metal or ceramic substrates that were used for filtration. Ceramic devices focused on wall-flow filtration, a concept in which exhaust gases are forced to flow through a semi-permeable ceramic substrate. Gases pass through the substrate while particulate matter is trapped on the upstream side of the substrate. In all but the hottest applications, external means of regeneration were required; these included electrical resistance heating, flame heating, and other means of raising the device temperature high enough to promote oxidation of the stored particulate. More recently, European experience has focused on the use of this type of device in concert with various fuel-borne catalysts. Demonstrations of the concept have also been accomplished in the U.S., but the devices are to date not in general use (6-14).

Another recent development in DPF technology is the washcoating of the base filter element with a mixture of catalytic agents. By including catalytic agents, the temperature required to promote oxidation of the particulate is lowered to a more realistic level. This reduction in temperature requirement, it is hoped, will allow exhaust heat alone to promote regeneration of the filter. The lower temperature also reduces substrate failures (due to thermal stress) that were not uncommon with the supplemental heating techniques mentioned above. Because this device is a filter, its differential pressure at a constant flow rate increases with the amount of particulate stored in the device. During regeneration, the stored particulate is burned to $\mathrm{CO}_{2}$ and flows through the filter, reducing the differential pressure across the device. One undesirable side effect of adding noble metals in the washcoat is that the CDPF can, under some conditions, convert the $\mathrm{SO}_{2}$ in the exhaust to $\mathrm{H}_{2} \mathrm{SO}_{4}$ resulting in sulfate PM emissions.

\section{RESEARCH VEHICLE}

The testbed for this research project was a 1999 Mercedes A170 CDI (see Figure 1). The vehicle's curb weight was $1,095 \mathrm{~kg}$, as equipped with a 5 -speed manual transaxle and 1.7 liter diesel engine. The engine is a turbocharged, intercooled, 4-valve-per-cylinder, direct-injection design that produces $66 \mathrm{~kW}$ at $4,200 \mathrm{rpm}$. This engine produces a maximum torque of $180 \mathrm{Nm}$ from $1,600 \mathrm{rpm}$ to 3,200 rpm. The application utilizes exhaust gas recirculation (EGR) for NOx control, plus two oxidation catalysts to control carbon monoxide, hydrocarbons, and PM emissions. The first of these is close-coupled directly to the outlet of the turbocharger, with the second catalyst mounted in an underfloor configuration. The vehicle was first sent to a nearby research facility for break-in mileage accumulation $(6,500 \mathrm{~km})$ on a closed-course. The breakin mileage accumulation was conducted using ultra low sulfur fuel. Following this break-in period, the vehicle was thoroughly instrumented. Relevant temperatures, pressures, accelerator pedal position, engine speed, and other measurements were collected using an in-vehicle data acquisition system. This same data acquisition system also collected gas analysis and other data during transient chassis dynamometer tests. The A170 did not have an air conditioning system installed.

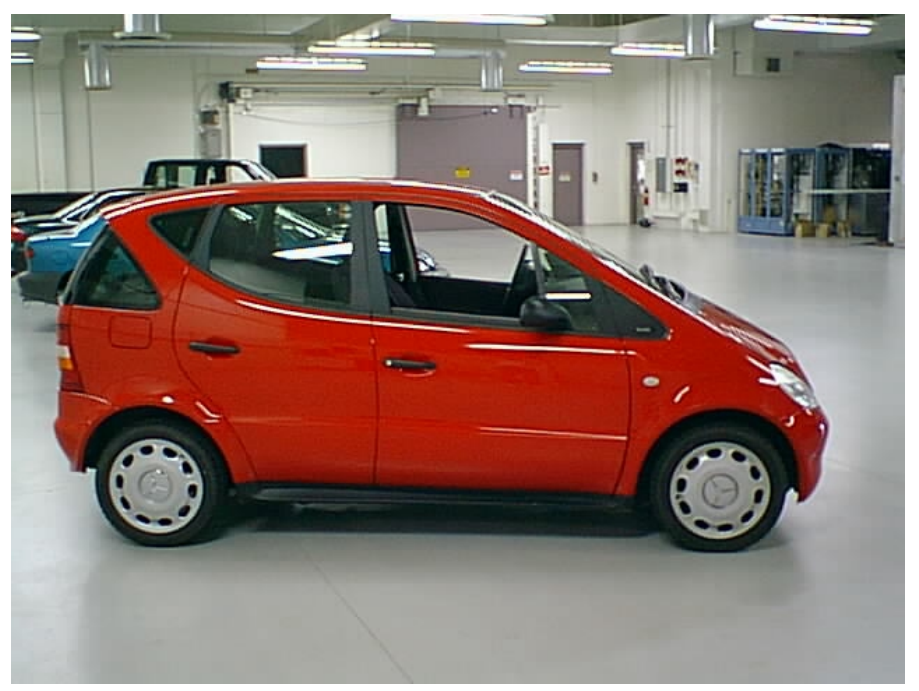

Figure 1. Mercedes A170 research vehicle.

\section{TEST FUELS}

Phillips ultra-low sulfur diesel fuel was used for initial engine and catalyst break-in, and the same fuel doped to various sulfur levels was used in all of the evaluations for this project. The fuel specifications were the same as those from the DECSE program (see Table 1). The DECSE fuels utilized an ultra-low sulfur ( $3 \mathrm{ppm}$ ) base fuel that was doped with sulfur compounds to achieve the higher sulfur (30- and 150-ppm) blend fuels. This was done so that fuel properties other than the sulfur level would be the same for all of the test fuels. The sulfur compounds used for doping the fuels included dibenzo(b)thiophene, benzo(b)thiophene, di-t-butyl disulfide, and ethyl phenyl sulfide. These compounds were selected because they are likely to remain in highlyhydrotreated fuels and because they are commercially available in large quantities. The DECSE program presented a more in-depth discussion of fuel properties and their selection (1). The OEM catalysts, engine-out configuration, and catalyzed diesel particulate filter evaluations were conducted with 3-, 30-, and 150-ppm sulfur fuels. Evaluations were also conducted on a NOx adsorber using 3- and 30-ppm sulfur fuels. 
Table 1. DECSE program base fuel properties.

\begin{tabular}{|c|c|c|}
\hline $\begin{array}{l}\text { 19-Apr-99 } \\
\text { Property }\end{array}$ & ASTM & $\begin{array}{c}\text { As } \\
\text { Measured }\end{array}$ \\
\hline Density & $\begin{array}{l}\text { D1298/D40 } \\
52\end{array}$ & 826.1 \\
\hline Viscosity@40C,mm2/s & D445 & 2.42 \\
\hline Distillation $\quad$ IBP, C & D86 & 185 \\
\hline $5 \%$ recovery, $\mathrm{C}$ & D86 & 198 \\
\hline $10 \%$ recovery, C & D86 & 207 \\
\hline $20 \%$ recovery, C & D86 & 222 \\
\hline $30 \%$ recovery, C & D86 & 238 \\
\hline $40 \%$ recovery, C & D86 & 251 \\
\hline $50 \%$ recovery, C & D86 & 259 \\
\hline $60 \%$ recovery, C & D86 & 266 \\
\hline $70 \%$ recovery, C & D86 & 274 \\
\hline $80 \%$ recovery, C & D86 & 287 \\
\hline $90 \%$ recovery, C & D86 & 314 \\
\hline $95 \%$ recovery, C & D86 & 338 \\
\hline FBP & D86 & 350 \\
\hline Carbon, mass \% & D5291 & 86.3 \\
\hline Hydrogen, mass $\%$ & D5291 & 13.4 \\
\hline Sulfur, ppm & D4045 & 3.1 \\
\hline Average molecular & r weight & \\
\hline Saturates, vol. \% & D1319 & 70.7 \\
\hline Olefins, vol \% & D1319 & 2.3 \\
\hline Aromatics, vol. \% & D1319 & 27.0 \\
\hline Aromatics, wt. \% & D5186 & 28.5 \\
\hline Polyaromatics, wt. \% & D5186 & 9.6 \\
\hline Heat Comb, net, MJ/kg & D240 & 43.1 \\
\hline Cetane number & D613 & 44.8 \\
\hline Cetane index & D976 & 53.6 \\
\hline Cloud point, C & D2500 & -21.0 \\
\hline $\begin{array}{l}\text { HFRR lubricity, um } \\
\text { (without lubricity additive) }\end{array}$ & D6079 & 635 \\
\hline $\begin{array}{l}\text { HFRR lubricity, um } \\
\text { (with lubricity additive) }\end{array}$ & D6079 & 355 \\
\hline
\end{tabular}

\section{EXPERIMENTAL FACILITIES AND TEST CYCLES}

A full-flow constant volume dilution tunnel was used for collecting particulate and bag emissions. Emissions benches with the standard heated chemiluminescence (HCLD) analyzers, heated flame ionization detectors (HFIDs), paramagentic detectors (PMDs), and nondispersive infrared (NDIR) analyzers were used to monitor raw and dilute exhaust gas during all evaluations. PM samples were collected using 47-millimeter $(\mathrm{mm})$ diameter Pall TX40HI120 filters. The dynamometer is a twin-roll eddy current type, which has been shown to emulate certification-type tests for research purposes (15). This equivalency was re-verified for this project by conducting repetitive certification tests at an independent certification laboratory with the A170 test vehicle in OEM configuration.

A modified federal test procedure (FTP) was used to enhance particulate sample collection. The FTP calls for 3 phases, or bags. Bag 1 is the first 505 seconds of the cycle, which includes a cold start. Bag 2 is the next 867 seconds of the cycle. The vehicle is soaked for 10 minutes, and the bag 1 drive cycle is repeated for bag 3 . The calculation of the composite emissions from the 3 bags assumes that a $4^{\text {th }}$ bag identical to bag 2 is collected. The modified FTP consists of only 2 bags: bag 1 includes the entirety of phases 1 and 2 from the FTP, while bag 2 includes phase 3 from the FTP plus an actual test of phase 4 that is normally assumed to be identical to phase 2 . In this way, both methods of conducting the FTP produce the same emissions results. However, given that each phase of the modified FTP is 1372 seconds long, a larger particulate sample can be collected, allowing greater accuracy in measuring and analyzing the particulate sample. Triplicate runs of the modified FTP were conducted for each fuel and exhaust configuration.

The high-speed, high-load US06 cycle was conducted following the second phase of the modified FTP. The SC03 "air conditioning" cycle was run following an FTP bag 1 ("hot 505") preconditioning. The SC03 cycle was run at ambient laboratory conditions (nominally $75 \mathrm{~F}$ ). The test vehicle is not equipped with air conditioning, so engine loads were not representative of an actual SC03. However, because the SC03 contains micro-transients that are different from those in the FTP, the vehicle was tested on this cycle despite the absence of air conditioning or the ability to control test cell conditions. All test cycles were run in triplicate for each fuel and exhaust system configuration.

\section{BASELINE EVALUATIONS}

The vehicle's emissions were first determined with the OEM emissions control devices in place. The evaluations were carried out over a three-day period (required for three cold-start FTPs) for each fuel, followed by a fuel change and evaluations of the next fuel. Tests began with the 3 ppm sulfur fuel, and the fuels were tested in order of increasing sulfur, with a return to the $3 \mathrm{ppm}$ fuel following the $150 \mathrm{ppm}$ tests. Following evaluations of the OEM catalysts, the exhaust system was removed and the vehicle fitted with a straight pipe for measurement of engine-out emissions. The same fuels were again evaluated in order of increasing sulfur content, but no repeats of the 3ppm tests were conducted for this condition.

The OEM FTP results show that the A170, though not certified for sale in the United States, produces emissions that fall within US Tier 1 full useful life standards without modification (see Table 2). For comparison purposes, the A170 was tested at an independent certification laboratory to provide a set of comparison data to re-verify the validity of results from the non-certification chassis dynamometer used for this project. These data (Table 1) show that although the ORNL emissions results are slightly lower than the independent lab, NOx and PM results are within $22 \%$ and $15 \%$ respectively. Furthermore, the fuel economy results agree to within $5 \%$. Other programs have 
established that site-to-site emissions test results can vary by more than $50 \%$, with most results demonstrating less than $30 \%$ variability (16).

Table 2. FTP emissions for OEM and engine-out exhaust configurations

\begin{tabular}{|c|c|c|c|c|c|}
\hline $\begin{array}{l}\text { Fuel/Exhaust } \\
\text { Condition }\end{array}$ & $\begin{array}{l}\mathrm{CO} \\
\mathrm{g} / \mathrm{mi}\end{array}$ & $\begin{array}{l}\text { THC } \\
\mathrm{g} / \mathrm{mi}\end{array}$ & $\begin{array}{l}\text { NOx } \\
\text { g/mi }\end{array}$ & $\begin{array}{l}\text { PM } \\
\mathrm{g} / \mathrm{mi}\end{array}$ & MPG \\
\hline 3 PPM & & & & & \\
\hline OEM & 0.17 & 0.025 & 0.587 & 0.073 & 43.9 \\
\hline 30 PPM & & & & & \\
\hline OEM & 0.124 & 0.026 & 0.609 & 0.08 & 42.3 \\
\hline 150 PPM & & & & & \\
\hline OEM & 0.137 & 0.042 & 0.575 & 0.082 & 42.9 \\
\hline 3 PPM & & & & & \\
\hline OEM Repeat & 0.125 & 0.046 & 0.581 & 0.077 & 43.5 \\
\hline Cert. Lab & & & & & \\
\hline $\begin{array}{c}3 \text { PPM } \\
\text { OEM }\end{array}$ & 0.134 & 0.052 & 0.725 & 0.085 & 45.6 \\
\hline 3 PPM & & & & & \\
\hline Eng-Out & 2.208 & 0.303 & 0.601 & 0.131 & 43.5 \\
\hline 30 PPM & & & & & \\
\hline Eng-Out & 2.179 & 0.425 & 0.615 & 0.135 & 42.9 \\
\hline 150 PPM & & & & & \\
\hline Eng-Out & 2.063 & 0.419 & 0.606 & 0.142 & 42.6 \\
\hline
\end{tabular}

${ }^{\star}$ Reported values are the average results of three tests.

Although diesel vehicles are not currently subjected to the US06 and SC03 cycles, Tier 2 regulations will require these cycles in the near future. Therefore, the OEM emissions control system was also evaluated using both of these relatively new cycles. The results from the US06 are included as Table 3 . Because the vehicle is not equipped with air conditioning and because the SC03 emissions results always fell between those of the FTP and US06, the SC03 results are not specifically tabulated in this paper. The standard deviations of the emissions results are not tabulated, however, for NOx and PM results the standard deviations were generally about $5 \%$ of the average result. The standard deviations of the fuel economy results were generally about 1 mile per gallon or less. $\mathrm{CO}$ and THC variability was higher than for NOx and $\mathrm{PM}$, owing both to experimental scatter and the very low quantities of these pollutants emitted, particularly with the results from the vehicle in the OEM condition.

\section{Table 3. USO6 emissions for OEM and engine-out} exhaust configurations

\begin{tabular}{|c|c|c|c|c|c|}
\hline $\begin{array}{l}\text { Fuel/Exhaust } \\
\text { Condition }\end{array}$ & $\begin{array}{l}\mathrm{CO} \\
\mathrm{g} / \mathrm{mi}\end{array}$ & $\begin{array}{l}\text { THC } \\
g / m i\end{array}$ & $\begin{array}{l}\text { NOx } \\
g / m i\end{array}$ & $\begin{array}{l}\text { PM } \\
\mathrm{g} / \mathrm{mi}\end{array}$ & MPG \\
\hline $\begin{array}{l}\text { PPM } \\
\text { OEM }\end{array}$ & 0.02 & 0.013 & 1.195 & 0.115 & 43.2 \\
\hline $\begin{array}{c}30 \text { PPM } \\
\text { OEM }\end{array}$ & 0.023 & 0.014 & 1.346 & 0.134 & 42.2 \\
\hline $\begin{array}{c}150 \text { PPM } \\
\text { OEM }\end{array}$ & 0.035 & 0.025 & 1.277 & 0.153 & 42.2 \\
\hline $\begin{array}{c}3 \text { PPM } \\
\text { OEM Repeat }\end{array}$ & 0.02 & 0.023 & 1.286 & 0.148 & 42.4 \\
\hline $\begin{array}{l}3 \text { PPM } \\
\text { Eng-Out }\end{array}$ & 0.953 & 0.158 & 1.289 & 0.176 & 41.2 \\
\hline $\begin{array}{l}30 \text { PPM } \\
\text { Eng-Out }\end{array}$ & 0.963 & 0.155 & 1.332 & 0.184 & 41.0 \\
\hline $\begin{array}{l}150 \text { PPM } \\
\text { Eng-Out }\end{array}$ & 1.185 & 0.133 & 1.338 & 0.213 & 41.1 \\
\hline
\end{tabular}

${ }^{*}$ Reported values are the average results of three tests.

Fuel sulfur level had little apparent effect on the emissions from the OEM devices. It is possible that small detrimental effects from sulfur may be masked by experimental variability, however. Comparisons between the OEM devices and engine-out configuration also confirm that the OEM devices are very effective at reducing the levels of $\mathrm{CO}$, unburned hydrocarbon emissions, and soluble organic PM emissions, but have little effect on NOx emissions. Neither the fuel sulfur level nor the drive cycle significantly impacts these results. Close inspection of the instantaneous NOx concentrations before and after the catalysts did show some NOx reduction during periods of idle, but the effect of this phenomenon on NOx mass emissions was small and not present at higher loads. 
$\mathrm{NO}$ and $\mathrm{NO}_{2}$ concentrations were measured during the engine-out evaluations. It is noteworthy that under lightload conditions (including some acceleration events) the exhaust $\mathrm{NOx}$ can be nearly half $\mathrm{NO}_{2}$ before dilution. For both the OEM and engine-out exhaust configurations, the cold-start phase of the FTP demonstrated very slight increases in NOx emissions compared with the hot-start phase.

The OEM emissions control devices did provide partial reduction of the particulate mass emissions when compared with engine-out results. In anticipation of this result and in an effort to more fully characterize the particulate emissions, fractionation of the particulate samples was performed for both the OEM (Figure 2) and engine-out (Figure 3) configurations. The fractionation examined the contributions of wet sulfates, nitrates, soluble organics, and soot to the total PM measurement. In examining the sulfate contribution to the total PM mass, it is important to account for the amount of water absorbed by the sulfate PM that is not accounted for by the subsequent sulfate extraction analyses. For this project, the wet sulfate content was taken to be 2.3 times the extracted sulfate mass (4).

The total PM mass for the OEM device tests was always lower than the soot contribution alone during engine-out tests. This is consistent with oxidation of the soluble organic fraction (SOF) of the PM by the OEM catalysts. This explanation is also evidenced by the relatively high SOF present in the engine-out results (approximately 30\% of the PM mass regardless of cycle) compared to the OEM results (approximately $10 \%$ of the PM mass regardless of cycle). It also appears that the OEM catalysts remove a small portion of the PM that is reported as soot. The effect is small, but appears to be significant. The cold-start portion of the FTP showed slightly higher PM mass emissions than the hot start. The fractionations show that this difference appears mainly due to increased soot formation during the cold-start phase although there also appears to be a lower level of oxidation of the SOF during the cold-start phase. The fractionations also show that $\mathrm{SO}_{2}$-to-sulfate conversion was insignificant for the OEM catalysts.

The exhaust temperature for the FTP was as high as 300 degrees Celcius (at the turbocharger exit), but only during a small portion of the cycle. For the remainder of the FTP, the exhaust temperature rarely exceeded 250 degrees and averaged 190 - 200 degrees. The US06 produces exhaust temperatures of up to 400 degrees briefly, with most points between $300-350$ degrees, but with significant periods at low temperature during deceleration events. The average US06 exhaust gas temperature was 290 - 300 degrees. The SC03 produced exhaust temperatures very similar to the FTP, with only a few brief excursions above 250 degrees.

Although no significant sulfur effect on the SOF, sulfate mass, or nitrate mass was discovered, the mass of soot increases slightly with sulfur level. The data supports this trend regardless of drive cycle or fuel sulfur level. Similar results have been shown in some results from the DECSE program as well, and are not explained (4). It is possible that unusual sulfur compounds are being deposited as PM that are not accounted for by PM extraction analyses. It does not seem likely that soot formation within the cylinder should be so impacted by sulfur levels as low as those tested here. The lack of high levels of sulfur dioxide to sulfate conversion by the OEM catalysts is also significant. This lack of conversion is probably due to the very low exhaust temperatures, as this conversion is known to be very significant for heavy-duty engines where the duty cycle results in relatively high exhaust temperatures for diesel engines (4). $\mathrm{NO}_{2}$-to-nitrate conversion, also an issue for heavy-duty engines, does not appear significant for the OEM devices as evaluated in this light-duty application.

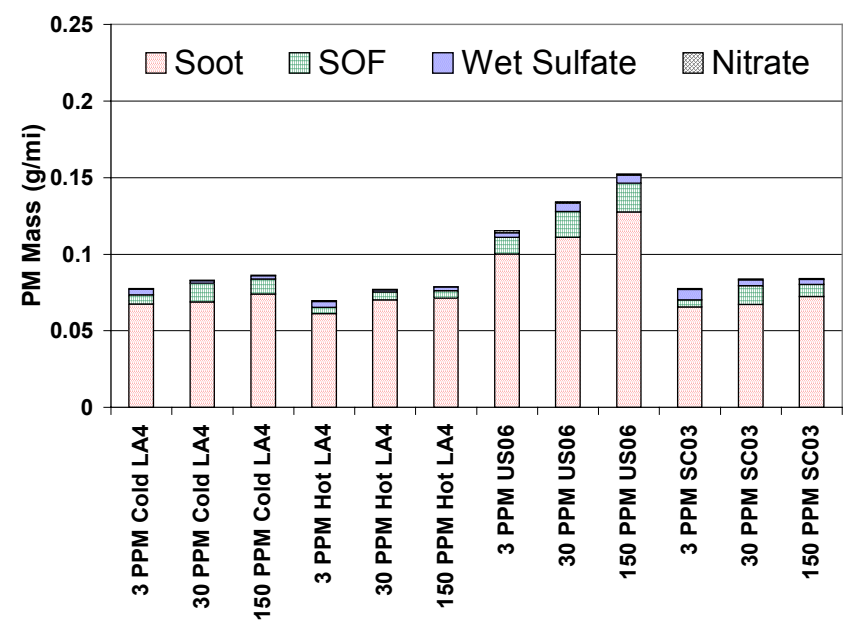

Figure 2. Particulate fractionation for the OEM exhaust system configuration (average of 3 tests).

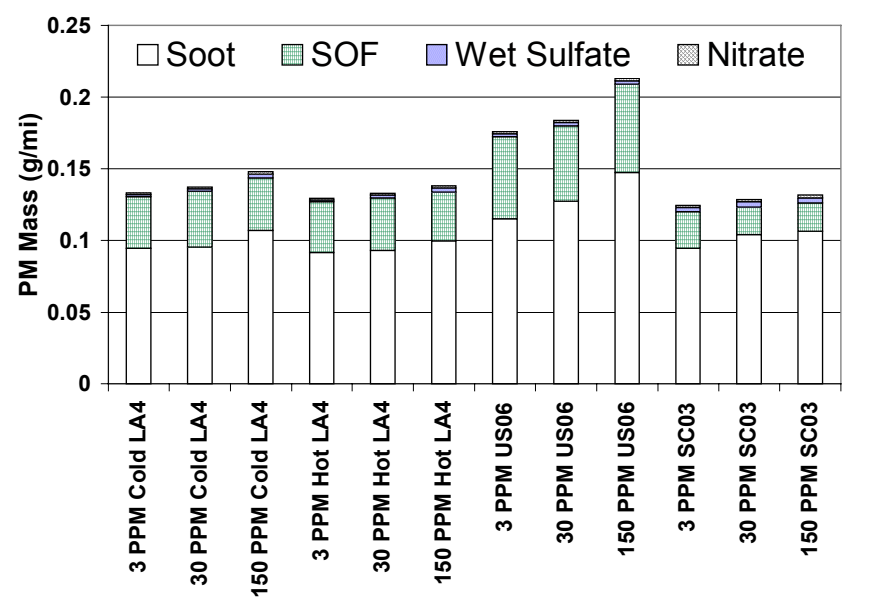

Figure 3. Particulate fractionation for the engine-out exhaust system configuration (average of 3 tests). 


\section{CDPF EVALUATION}

Following the baseline evaluations, a CDPF was mounted in an underfloor configuration (approximately 2 meters from the turbocharger exit) on the A170. The CDPF (approximately 2.5 liters in volume) was provided by the Manufacturers of Emissions Controls Association (MECA). Due to spacial constraints in the engine compartment of the $A 170$, it was not possible to mount the device closer to the engine within the timeframe of this project. In order to reduce the amount of heat lost to the atmosphere from the exhaust gases prior to the CDPF, a fibrous exhaust insulation wrap was used to insulate the exhaust system from the turbocharger exit to the outlet of the CDPF. A 0.8-millimeter diameter thermocouple was installed in the inlet of the CDPF. The thermocouple was threaded into one of the catalyst passages to provide measurements of the catalyst temperature. Thermocouples were also installed at the inlet and outlet of the device to measure the bulk gas temperature. Finally, a differential pressure transducer was installed to determine the differential pressure across the CDPF.

Prior to beginning the evaluations of the device, a number of drive cycles were conducted to both fine-tune the test procedure and to build up PM on the CDPF. These tests were conducted with $3 \mathrm{ppm}$ sulfur fuel and constituted several hours of break-in prior to the beginning of reportable evaluations. The first $3 \mathrm{ppm}$ sulfur tests were then completed.

Based on previous experience, it was hoped that the CDPF would be completely regenerated during the hightemperature portions of the US06 cycle (17). At the end of the initial $3 \mathrm{ppm}$ sulfur tests, an extended cruise at approximately 85 miles per hour demonstrated that in fact, substantial amounts of PM remained stored on the device even after the US06 cycle. Therefore, the test protocol was changed to include a modal 85-mile per hour burnoff of the device prior to changing the fuel for the next group of tests. The burnoff condition was selected because the road load for this vehicle at approximately 85 miles per hour resulted in a CDPF surface temperature just in excess of 400 degrees Celcius. As the device regenerates, the differential pressure (DP) across it decreases slowly. The rate of change of DP is a function of the exhaust flow rate, CDPF temperature, the PM production rate, and the amount of PM stored on the device. Therefore, the length of the burnoff was not constant; rather, the tests continued until the DP dropped to a stable value. In all burnoff tests particulate samples were collected to insure that the stored PM was oxidized as opposed to being emitted during the regeneration process.

Following the initial 3-ppm tests, the 30-ppm sulfur tests and a burnoff test were conducted. $150 \mathrm{ppm}$ sulfur tests were then completed with a $150 \mathrm{ppm}$ burnoff test, and finally $3 \mathrm{ppm}$ repeat tests were completed. Preliminary tests conducted during the break-in period for the CDPF had shown that particulate sample filters would need to be exposed to multiple tests in order to collect enough particulate for analysis. Therefore, one filter was used to collect PM for each drive cycle for each fuel. This allowed 3 identical repeat tests to be sampled on each sample filter, allowing the collection of enough PM for analysis. Each burnoff test utilized one particulate sample filter. All of these filters were subsequently fractionated to determine the wet sulfate, nitrate, soluble organic, and soot contributions to the total PM measurement.

\section{CDPF RESULTS}

The CDPF reduced $\mathrm{CO}$ and $\mathrm{HC}$ emissions at approximately the same efficiency as the combination of two OEM catalysts. It also demonstrates a small reduction of NOx emissions for the FTP cycle compared to the OEM catalysts, but this effect may have been due in part to differences in exhaust backpressure. This effect could also be due in part to oxidation of $\mathrm{PM}$ by $\mathrm{NO}_{2}$ resulting in slight reductions in $\mathrm{NO}_{2}$ emissions. In either case, the reductions are small enough to be insignificant. There do not appear to be measurable short-term fuel-sulfur effects on the ability of the CDPF to treat these pollutants (see Figures 4-6). The SC03 results that are shown are not indicative of results that might be expected if air conditioning had been used during the tests. The engineout exhaust temperature was not significantly different from the OEM and engine-out conditions during the CDPF evaluations.

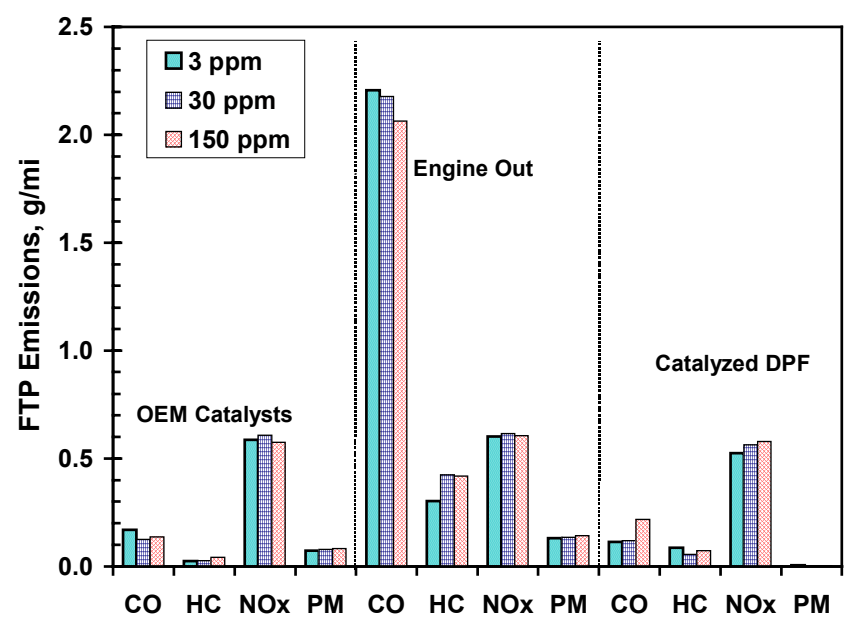

Figure 4. CDPF FTP results compared to OEM and engine-out configurations (average of 3 tests).

The reduction in particulate emissions from use of the CDPF is dramatic. The PM emissions were reduced to less than $0.01 \mathrm{~g} / \mathrm{mi}$ for all of the drive cycles and fuel sulfur levels (see Figure 7). Two measurements (tunnel blanks) of the dilution tunnel PM background are also shown in Figure 7. The first of these tests was conducted just before the CDPF evaluation, and the second just after the CDPF evaluation. The samples were gathered as if the 


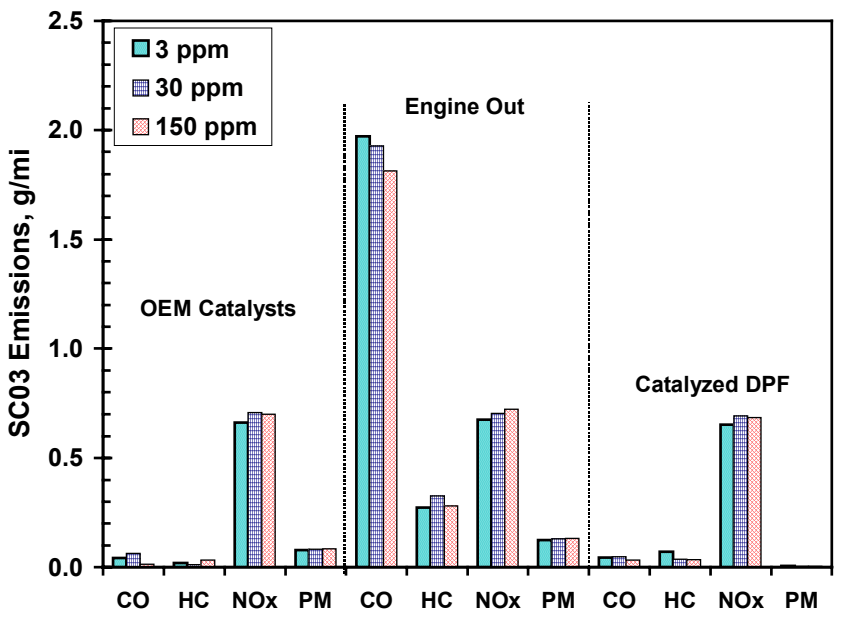

Figure 5. CDPF SC03 results compared to OEM and engine-out configurations (average of 3 tests).

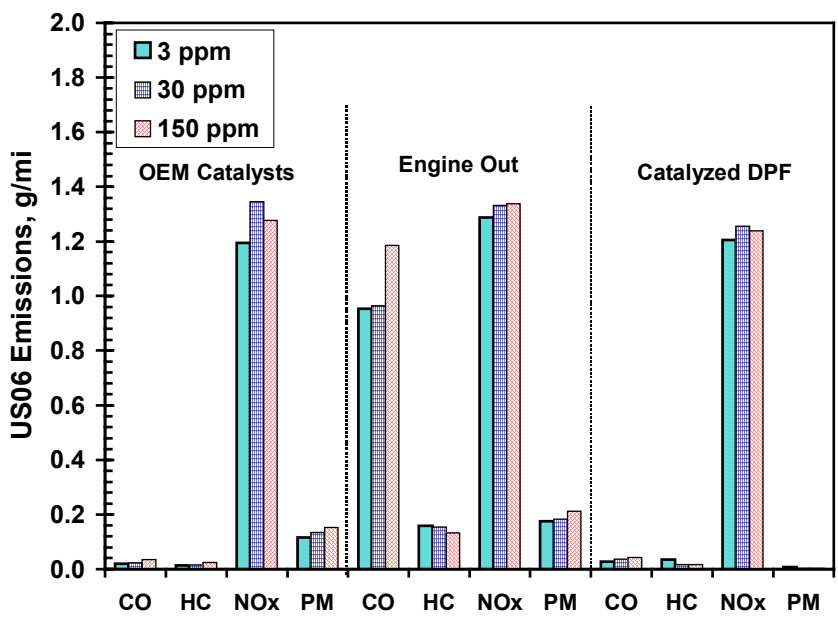

Figure 6. CDPF US06 results compared to OEM and engine-out configurations (average of 3 tests).

test were an LA4 cycle $(1,372$ seconds of flow through the dilution tunnel and onto the sample filter). The results were expressed in $\mathrm{g} / \mathrm{mi}$ by considering the accumulated PM (a few tens of micrograms) to have accumulated on the sample filter during the 7.45 miles of an LA4 cycle. In this way it was possible to estimate the contribution of PM adhering to the dilution tunnel walls to the measured PM result. The two tests did show that the background PM began at a level of $0.0026 \mathrm{~g} / \mathrm{mi}$ and concluded at a level of $0.0012 \mathrm{~g} / \mathrm{mi}$. As there is no means by which to accurately determine the rate that the tunnel background declined, the measured results for the drive cycle tests were not corrected for the background readings. However, the background PM levels were approximately $30-50 \%$ of the measured test results. In understanding the magnitude of this background measurement, it is useful to compare it with ambient air $\mathrm{PM}_{2.5}$ standards. If the U.S. 1-hour ambient air $\mathrm{PM}_{2.5}$ standard of 15 micrograms per cubic meter is taken as a mass concentration of PM in the tunnel and expressed as a $\mathrm{g} / \mathrm{mi}$ result for an LA4 as was shown for the background readings, the result is $0.0008 \mathrm{~g} / \mathrm{mi}$.
This comparison demonstrates that the dilution tunnel background levels are only marginally higher than ambient air quality standards. This level of background is not problematic for conducting tests of typical diesel vehicles at a $0.1 \mathrm{gram} / \mathrm{mile}$ standard, but becomes very significant during efforts to measure levels 10 times lower. Because of the high background relative to measured values and because of typical test-to-test variability, not all of the variations in the PM shown in Figure 7 are considered significant. However, it seems likely that the results from the initial tests with the 3-ppm sulfur fuel are higher because of the higher background measured just prior to beginning those tests. Furthermore, the difference in the $\mathrm{g} / \mathrm{mi}$ results for the initial and the final tests with the 3-ppm sulfur fuel differ by an amount that is almost identical to the difference in the two background PM measurements. The results shown in Figure 7 have not been corrected to account for the background measurements.

As noted previously, $\mathrm{SC0} 3$ results are not indicative of results that might be expected if air conditioning had been used during the tests. The results show that very low levels of PM emissions are achievable. Fuel sulfur does not seem to have a significant effect on the PM emissions when using a CDPF on typical light-duty driving schedules. Calculation of the standard deviation of the PM results shown in Figure 7 was not possible because each triplicate test sequence used only one sample filter. However, estimates of the measurement uncertainty indicate less than $10 \%$ error. As discussed previously, some estimates of test-to-test variability indicate an uncertainty of around $15 \%$. Applying this level of uncertainty to the PM results shows that some of the differences in the results are not statistically significant but the results remain below 0.01 $\mathrm{g} / \mathrm{mi}$.

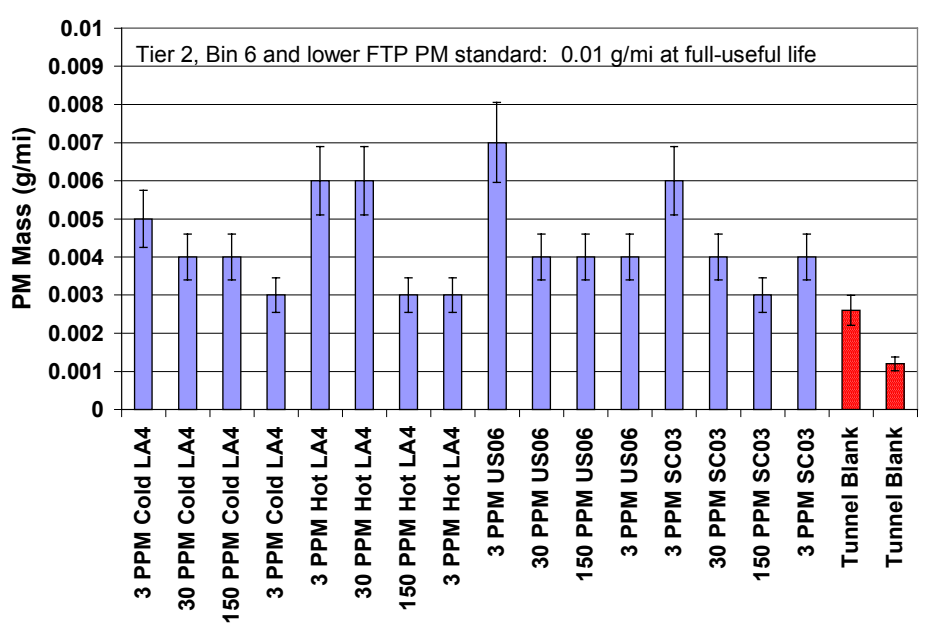

Figure 7. CDPF particulate mass results for all test cycles (average of 3 tests on a single sample filter).

Particulate fractionation was conducted for the CDPF particulate sample filters. Although the very small amount of collected mass made the analyses difficult some very 
significant results were obtained. The CDPF is known to produce very high $\mathrm{SO}_{2}$-to-sulfate conversion rates when used on heavy-duty engines (4). However, the particulate sample filter analyses for this project did not show any significant sulfate mass for any of the drive cycles. Nitrate emissions were similarly insignificant.

The soluble organic contribution to PM indicates a qualitative dependence on the drive cycle. During the hotstart phase of the FTP, significant fractions of the emitted PM are soluble organic aerosols. These aerosols do not appear to be present in any other driving condition, including the cold-start phase of the FTP. One possible explanation for this behavior is that these aerosols do not become particles until the exhaust dilution process occurs. On the cold-start FTP, these compounds may be cool enough to condense upstream of the CDPF and be captured and treated in later parts of the cycle. During the hot-start portion of the FTP, the exhaust may be warm enough for these compounds to remain gaseous and pass through the filter, which is not yet hot enough to oxidize them, leaving them to condense in the dilution tunnel, forming particles. On the US06 cycle, if these compounds are emitted, the CDPF may be hot enough to oxidize them, so they do not appear as PM. Furthermore, the SOF fraction shows a slight increase with increasing fuel sulfur level. This perhaps demonstrates a very small deleterious effect from the sulfur on oxidation of SOF. However, the amount of mass in question is so small as to be nearly negligible, although the effect is orderly enough to cast doubt on analysis error as the cause of the discrepancy.

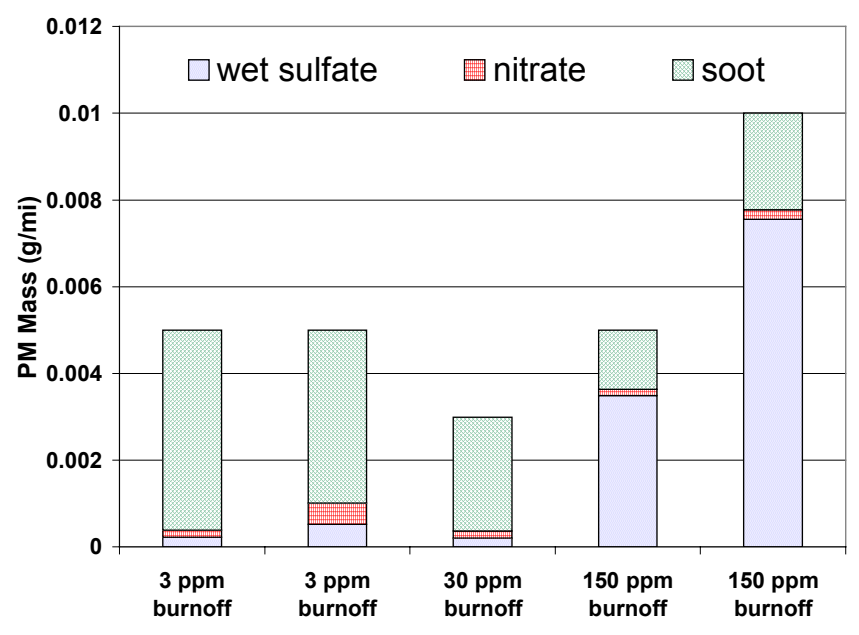

Figure 8. Particulate fractionations for burnoff tests.

The burnoff tests also produced very low PM emissions (see Figure 8). In all cases, the burnoff tests produced PM emissions at or below $0.01 \mathrm{~g} / \mathrm{mi}$. Because of the extreme exhaust temperatures and flows for these tests, the dilute exhaust mixture temperature was higher than desirable. Therefore, these emission rates should be considered approximate. However, the authors believe them to be correct because the CDPF was hot enough to fully oxidize any soluble organic compounds that the unusually high mixture temperature may have prevented from condensing in the dilution tunnel. Furthermore, the vapor pressure of sulfuric acid at these temperatures is negligible $(1 \mathrm{~mm} \mathrm{Hg}$ at $140 \mathrm{C}$ ), lending confidence that sulfate emissions were not volatilized rather than being captured by the sample filters.

Fractionation analysis of these filters showed insignificant amounts of sulfate mass on the 3ppm and $30-p p m$ sample filters, but a very high wet sulfate content (more than $70 \%$ of the collected mass) on the 150-ppm sample filters. Although in the $3 \mathrm{ppm}$ and $30 \mathrm{ppm}$ cases the sulfate mass is probably negligible, a trend of increasing sulfate mass with increasing fuel sulfur level is observed during the burnoff tests. Two filters were collected for the initial 3 ppm case and for the $150 \mathrm{ppm}$ case in an effort to determine whether the sulfate conversion happens near the beginning of regeneration or the end of regeneration. Based on these filter analyses, it seems possible that more catalytic sites become available for sulfate conversion as stored soot is regenerated. This may indicate that the higher levels of PM associated with light-duty engine calibrations (compared with heavy-duty calibrations) reduce $\mathrm{SO}_{2}$ chemisorption and subsequent sulfate conversion in the CDPF during drive-cycle tests. Although the relative insignificance of sulfate emissions during the drive cycle tests is more likely the result of low exhaust temperatures, this high PM effect may also contribute to lowering sulfate conversion. It is also possible, however, that high-sulfate conversion happens during hightemperature but low-space velocity conditions. It is more typical in light-duty applications for the space velocity to be relatively high during high-temperature events. A more thorough study of exhaust sulfur compounds and their behavior would be of great value in understanding and reducing sulfate PM emissions under all driving conditions.

Given the relatively high fuel consumption rate for the vehicle at the burnoff condition, the amount of sulfate PM that was produced is far less than the amount that could be produced at the burnoff condition even if there were no stored $\mathrm{SO}_{2}$ whatsoever. (If $100 \%$ of the sulfur in the 150 ppm fuel were converted to wet sulfate at the burnoff condition, the sulfate PM emissions could be as high as $0.1 \mathrm{~g} / \mathrm{mi}$.) Therefore, it is impossible to determine whether the sulfate PM emissions resulted from $\mathrm{SO}_{2}$ stored in the soot filter during drive cycle tests or from $\mathrm{SO}_{2}$ generated by the engine during the burnoff test. On a fuel-burned basis, the total amount of $\mathrm{SO}_{2}$ that could have been stored on the CDPF during the 150-ppm fuel burnoff is roughly equal to the amount of $\mathrm{SO}_{2}$ produced during the entirety of the 150-ppm drive cycle tests. Either amount, if converted to sulfate, could result in sulfate emissions much higher than were observed during the burnoff tests. Given this level of uncertainty as to the level of sulfur storage by the CDPF and the very low PM emissions even during the burnoff condition, it does not seem likely that emissions were "stored" during the drive cycles only to be "released" 
during the burnoff. Hence, no efforts were made to apportion the burnoff test PM emissions to each individual drive cycle test result.

The fuel economy penalty associated with use of the CDPF is an important tradeoff for the emissions control benefit the technology offers. The tests conducted during this project did not demonstrate statistically significant differences in fuel economy between the OEM condition and the CDPF configuration. Stationary engine-based measurements (4) and rudimentary calculations of the magnitude of the fuel economy penalty based on flow and pressure data from this project suggest that the penalty should be on the order of $2-3 \%$ for the FTP cycle. This level of variation is lower than the generally accepted testto-test variability associated with repeat chassis dynamometer tests. Therefore, it is not possible to separate the fuel economy penalty from test variations. However, this fact alone reinforces the relatively minor fuel economy impact of this technology when used in a passive mode.

The increased exhaust flow restriction posed by the CDPF could significantly influence vehicle performance. This effect was not very pronounced except at high levels of performance. However, in a production environment designing for and maintaining acceptable levels of exhaust backpressure are important both for consistent performance and emissions control. The differential pressure for the CDPF was measured continuously during each test for this project. Figure 9 shows the maximum and average differential pressures for all of the tests. As expected, for a given fuel sulfur level and a given test cycle, the average and maximum differential pressures increased for each of the repeated tests. The initial $3 \mathrm{ppm}$ sulfur tests demonstrate some anomalies that occurred as a result of the CDPF conditioning prior to the beginning of tests, and are presented only for completeness. With the exception of the initial 3-ppm sulfur tests, the maximum differential pressure is maintained below $153 \mathrm{~mm} \mathrm{Hg}(6$ inches $\mathrm{Hg}$ ) for all test cases. It is not clear what effect air conditioner usage might have had on the differential pressures that were measured during the $\mathrm{SC} 03$ test had air conditioning been used during the test. Fuel economy losses as a result of the increasing backpressure for each replicate test were not statistically significant compared with accepted levels of test-to-test variability. The results qualitatively supported fuel economy penalties on the order of $2 \%$, as estimated and discussed previously.

Regeneration of the CDPF, as mentioned earlier, was not entirely passive. The engine-out exhaust temperature did not increase significantly as the differential pressure across the CDPF increased during any of the tests. Rather, the engine-out exhaust temperature remained within a few degrees of the same temperature that was measured during the engine-out and OEM evaluations. Thus, this data does not support the concept that increased exhaust backpressure might increase the exhaust temperature sufficiently to promote regeneration of the CDPF. For this project, regeneration was accomplished by driving the vehicle at a relatively high speed at road load to generate sufficient exhaust gas temperatures. (Extended highway cruise at $70 \mathrm{mph}$ was also shown to regenerate the device, but would require a longer period of time.) This was necessary, in part, because the CDPF could not be close-coupled in this vehicle in the short time frame of this project. However, the authors suggest that with close coupling of the device, continued improvement of this experimental device, and perhaps engine control accommodations for this technology, the necessary temperatures can probably be achieved to regenerate this type of device under normal driving conditions. Accomplishing this level of control of the regeneration process (or using fuel additives or other regeneration aids) will be critical to maintaining the exhaust backpressure at acceptable levels for commercial deployment of this technology. Preliminary research indicates that utilization of engine controls such as injection timing, EGR rates, and post-injection of fuel can provide large (greater than $100 \mathrm{C}$ ) increases in engine-out exhaust temperature for the regeneration of these types of devices (18). However, long-term evaluations of the effects of these strategies on the reliability of engines have yet to be conducted.

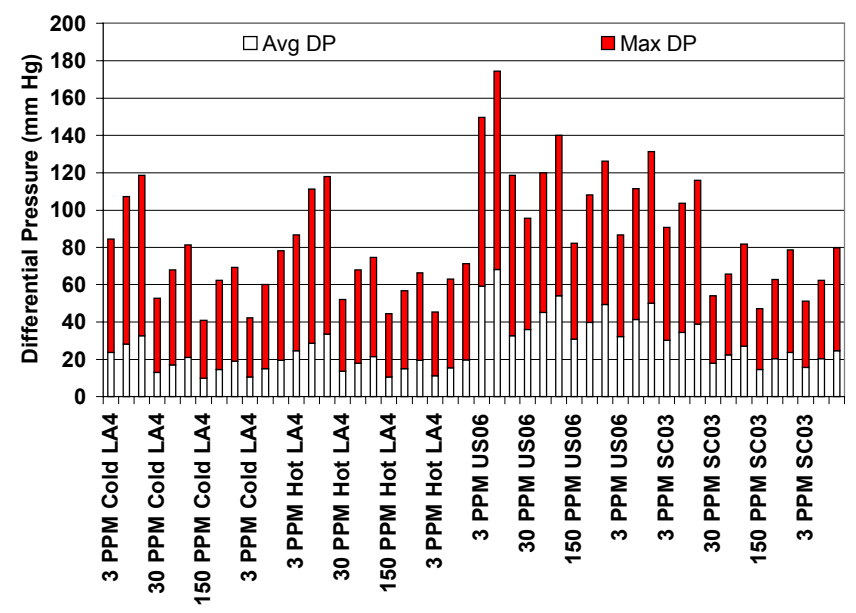

Figure 9. CDPF differential pressure for all tests.

It is worthy of note that the results that have been demonstrated during this project have been accomplished without any modification to the engine or engine control system. While these results are very promising indeed, the level of integration of this device into the vehicle system is not as high as that which might be expected in production from a manufacturer. Given advances in both $\mathrm{PM}$ and NOx emissions controls, it seems likely that these results will be eclipsed in the near future as a systems level approach to emissions control is taken. As this happens, improvements in particulate measurement and analysis techniques will be of critical importance in further uncovering important relationships in ever-shrinking particulate mass emissions. For example, the Code of Federal Regulations (CFR) recommends (but does not require) that the primary filter loading during an FTP test 
be at least 0.500 milligrams (17). The loading on the primary sample filter used for the triplicate FTP tests conducted during this project was less than 0.200 milligrams. Furthermore, the PM mass concentration in the dilution tunnel during the conducted tests was only about 4 times higher than the new 1-hour $\mathrm{PM}_{2.5}$ standard of 15 micrograms per cubic meter of ambient air (19).

Finally, the size distribution of the particulate emissions is becoming the focus of increasing concerns. Studies have shown that particulate emissions control devices may promote a higher level of ultra-fine and nano-particles than would otherwise be present in diesel exhaust plumes (20). These very small particles may pose a significant health concern. However, it has also been shown that the dilution ratio at which the particle size distribution is determined is itself a very important factor in the physics that determine the size distribution. Given that the dilution ratio is non-constant during transient drive cycle tests utilizing a full-flow dilution tunnel, any useful aerosol size measurements would need to be carried out modally, rather than over a transient cycle, at least until further refinements in dilution methodology are developed. The authors recognize the importance of characterizing the particulate size distribution and measuring the numbers of particles emitted, however, the scope of this study did not permit inclusion of these measurements.

In the future, the authors plan to include more in-depth study of the size distribution of particles as well as study of nitrous oxide $\left(\mathrm{N}_{2} \mathrm{O}\right)$, organo-nitrates, aldehydes, and other chemical species that may occur as a result of the use of advanced emissions control devices. Plans for future work also include research aimed at a better understanding of the fuel-sulfur and other fuel property effects on the performance of these types of emissions control technologies. Furthermore, simultaneous control of all of the criteria pollutants is required for vehicles to be sold in the U.S. and other countries. Evaluating multiple devices simultaneously was not within the scope of this project, but remains an important issue that must be addressed. In summary, while the results of the evaluations conducted during this project are very promising, they do not represent a claim by the authors that these technologies are ready for commercialization. In fact, much work remains to be done in order to allow the manufacturers to sell dependable vehicles that utilize these technologies.

\section{CONCLUSIONS}

- The CDPF has been demonstrated to reduce PM emissions well below $0.01 \mathrm{~g} / \mathrm{mi}$, including during device regeneration, over the U.S. FTP-75, US06, and SC03 (without air conditioning) cycles.

- The CDPF does not show significant degradation in performance over these cycles for fuel sulfur levels as high as $150 \mathrm{ppm}$, at least in the short term. (DECSE had previously shown no unrecoverable degradation in the longer term) (4).

- $\mathrm{SO}_{2}$-to-sulfate conversion by the CDPF was not significant during transient tests conducted for this project, except during regeneration with 150-ppm sulfur fuel. This is most likely due to very low exhaust temperature conditions although other factors may play a role in mitigating sulfate conversion.

- The CDPF was not fully passive in this application in that it required some thermal assistance for regeneration. However, further development, closecoupling, and appropriate engine controls may provide a path to allow regeneration during normal driving.

- Differential pressure across the CDPF can be kept to below $153 \mathrm{~mm} \mathrm{Hg}$ (6 inches $\mathrm{Hg}$ ) even under highspeed and wide-open throttle accelerations on the US06 cycle.

- No attempts were made to demonstrate the durability of this technology or its emissions reduction potential at the full-useful life of the vehicle. These are important points that must be addressed before manufacturers can be expected to put these kinds of technologies into general use.

- It is becoming increasingly challenging to make reliable, repeatable measurements of the regulated pollutants as the legislated maximum levels of these pollutants decrease. In the case of PM mass, this difficulty manifests itself not in the limit of instrument sensitivity, but in the sample collection process. These kinds of challenges may require new analytical methods in the near future to allow continued improvement of measurement reliability.

\section{ACKNOWLEDGMENTS}

The authors would like to acknowledge the U.S. Department of Energy for support of this work, particularly Mr. Peter Devlin, Office of Advanced Automotive Technology. Grateful acknowledgement is also due to members of MECA for furnishing the exhaust emission control devices and valuable technical guidance, and to the University of Tennessee for the use of the chassis dynamometer facility. Thanks also to the following ORNL staff: Jimmy Wade and Homer Tucker for performing PM sample analyses, John Storey for technical assistance, and Ralph McGill for programmatic oversight.

\section{DISCLAIMER}

The submitted manuscript has been authored by a contractor of the U.S. government under contract number DE-AC05-00OR22725. Accordingly, the U.S. government retains a nonexclusive, royalty-free license to publish or reproduce the published form of this contribution, or allow others to do so, for the U.S. government. 


\section{REFERENCES}

1. U.S. Department of Energy, Engine Manufacturers Association, Manufacturers of Emission Controls Association, "Diesel Emission Control Sulfur Effects (DECSE) Program - Phase I Interim Data Report No. 1: Phase 1 Interim Data," August 1999

2. U.S. Department of Energy, Engine Manufacturers Association, Manufacturers of Emission Controls Association, "Diesel Emission Control Sulfur Effects (DECSE) Program - Phase I Interim Data Report No. 2: NOx Adsorber Catalysts," October 1999

3. U.S. Department of Energy, Engine Manufacturers Association, Manufacturers of Emission Controls Association, "Diesel Emission Control Sulfur Effects (DECSE) Program - Phase I Interim Data Report No. 3: Diesel Fuel Sulfur Effects on Particulate Matter Emissions," November 1999

4. U.S. Department of Energy, Engine Manufacturers Association, Manufacturers of Emission Controls Association, "Diesel Emission Control Sulfur Effects (DECSE) Program - Phase I Interim Data Report No. 4: Diesel Particulate Filters Final Report," January 2000

5. Brian H. West and C. Scott Sluder. "NOx Adsorber Performance in a Light-Duty Diesel Vehicle." SAE\#2000-012912, Society of Automotive Engineers. Warrendale, 2000.

6. M. W. Vincent, P. Richards, and S. L. Cook. "Particulates Reduction in Diesel Engines Through the Combination of a Particulate Filter and Fuel Additive." SAE\#982654, Society of Automotive Engineers. Warrendale, 1998.

7. D. L. McKinnon, D. A. Pavlich, T. Tadrous, and D. Shepherd. "Results of North American Field Trials Using Diesel Filters with a Copper Additive for Regeneration." SAE\#940455, Society of Automotive Engineers. Warrendale, 1994.

8. Alejando F. Romero, Jorge Castrejon-Rodgrigues, and Rodolfo Serrano-Romero. "Self Regenerating Catalyzed Diesel Aftertreatment System." SAE\#950367, Society of Automotive Engineers. Warrendale, 1995.

9. Yiannis A. Levendis, Iraklis Pavlatos, and Richard F. Abrams. "Control of Diesel Soot, Hydrocarbon, and NOx Emissions with a Particulate Trap and EGR." SAE\#940460, Society of Automotive Engineers. Warrendale, 1994.

10. V. D. N. Rao, H. A. Cikanek, and R. W. Horrocks. "Diesel Particulate Control System for Ford 1.8L Sierra Turbo-Diesel to Meet 1997-2003 Particulate Standards." SAE\#940458, Society of Automotive Engineers. Warrendale, 1994.

11. Kaxushige Ohno, Koji Shimato, et al. "Characterization of SiC-DPF for Passenger Car." SAE\#2000-01-0185. Society of Automotive Engineers. Warrendale, 2000.

12. Matthias Bouchez and Jean Baptiste Dementhon. "Strategies for Control of Particulate Trap Regeneration." SAE\#2000-01-0472. Society of Automotive Engineers. Warrendale, 2000.

13. O. Salvat, P. Marez, and G. Belot. "Passenger Car Serial Application of a Particulate Filter System on a Common Rail Direct Injection Diesel Engine." SAE\#2000-01-473. Society of Automotive Engineers. Warrendale, 2000.
14. P. J. Richards, M. W. Vincent, and S. L. Cook. "Operating Experience of Diesel Vehicles Equipped with Particulate Filters and Using Fuel Additive for Regeneration." SAE\#2000-01-474. Society of Automotive Engineers. Warrendale, 2000.

15. Brian H. West, Ralph N. McGill, C. Scott Sluder, and Jeffrey W. Hodgson. "Data-Based Modal Emissions and Fuel Consumption Models for Traffic Assessments." Emission Inventory: Planning for the Future, Volume II, VIP-77. Air and Waste Management Association, 1997.

16. AAMA/AIAM FTP Ad Hoc Panel. "FTP Test Program Phase II Vehicle Correlation Program Test Results and Analysis." June 1994.

17. Code of Federal Regulations 40, Part 86, Subpart 112-91. U.S. Government Printing Office, 1995.

18. Matthias Bouchez and Jean Baptiste Dementhon. "Strategies for the Control of Particulate Trap Regeneration." SAE\#2000-01-0472. Society of Automotive Engineers. Warrendale, 2000.

19. "EPA's Revised Particulate Matter Standards Fact Sheet". United States Environmental Protection Agency, Office of Air \& Radiation, Office of Air Quality Planning \& Standards. July 17, 1997.

20. John M. E. Storey, C. Scott Sluder, Samual A. Lewis, and David K. Irick. "Exhaust Emissions Control Effects on Diesel Particulate Matter Characteristics." Proceedings of the 1999 Diesel Engine Emissions Reduction Workshop. July 1999.

\section{DEFINITIONS, ACRONYMS, ABBREVIATIONS}

CDPF - Catalyzed Diesel Particulate Filter

CO - Carbon Monoxide

DECSE - Diesel Emissions Control Sulfur Effects Program

DPF - Diesel Particulate Filter

DOE - U.S. Department of Energy

EGR - Exhaust Gas Recirculation

EPA - U.S. Environmental Protection Administration

FTP - Federal Test Procedure

$\mathrm{HC}$ - Hydrocarbons

HCLD - Heated Chemiluminescence Detector

HFID - Heated Flame Ionization Detector

MECA - Manufacturers of Emissions Controls Association

NDIR - Non-dispersive infrared detector

$\mathrm{NO}_{x}-$ Oxides of Nitrogen

$\mathrm{NO}_{2}$ - Nitrogen dioxide

OEM - Original Equipment Manufacturer

ORNL - Oak Ridge National Laboratory

PM - Particulate Matter

PMD - Paramagnetism Detector

ppm - parts per million

SC03 - U.S. SC03 light-duty drive cycle

$\mathrm{SO}_{2}$ - Sulfur dioxide

SOF - Soluble Organic Fraction (of particulate emissions)

THC - Total Hydrocarbons

US06 - US06 light-duty drive cycle 